\title{
OPEN Antibacterial and antibiofilm activities of cinnamon essential oil nanoemulsion against multi-species oral biofilms
}

\begin{abstract}
Yeo-Jin Jeong ${ }^{1}$, Hee-Eun Kim² ${ }^{2}$ Su-Jin $\mathrm{Han}^{2}$ \& Jun-Seon Choi ${ }^{2}$
Cinnamon essential oil (CEO) has antibacterial properties, but its ability to suppress the formation of multi-species oral biofilms has not been fully elucidated. This study evaluated the antibacterial and antibiofilm activities of cinnamon essential oil nanoemulsion (CEON) against oral biofilms formed using a microcosm biofilm model. The biofilms were formed on bovine enamel specimens over a 7-day period, during which all specimens were treated with one of three solutions: $5 \%$ CEON $(n=35), 0.5 \%$ cocamidopropyl betaine $(n=35)$, or $0.12 \%$ chlorhexidine gluconate $(\mathrm{CHX} ; n=35)$. Antibacterial and antibiofilm activities were determined by the red/green ratios (R/G values) of 7-day-old mature biofilms photographed with quantitative light-induced fluorescence-digital, the number of aciduric bacterial colony-forming units (CFUs) within each biofilm, and the absorbance of bacterial suspensions. One-way and repeated-measures analysis of variance were performed to compare differences among the three solutions. R/G values were lowest in the $0.12 \% \mathrm{CHX}$ group, but not significantly differ from the $5 \%$ CEON group. The number of CFUs and absorbance were lowest in the $5 \%$ CEON group. This study showed that nanoemulsified CEO inhibited the maturation of multispecies oral biofilms and the growth of oral microorganisms in biofilms, including aciduric bacteria that cause dental caries.
\end{abstract}

Dental caries and periodontal diseases are common worldwide and represent the main causes of tooth loss ${ }^{1}$. Careful management of oral biofilms, which consist of complex microbial communities, is critical to prevent the onset and progression of oral diseases ${ }^{2}$. Compared with planktonic bacteria, microbial communities that have formed biofilms are more resistant to external stress (e.g., nutrient depletion or toxic substance exposure), due to the presence of bacterial extracellular polysaccharides ${ }^{3,4}$. Therefore, residual oral biofilms comprising pathogenic bacteria that have not been removed for extended periods of time may be increasingly hazardous to oral health ${ }^{5}$.

Although biofilm removal is considered important for maintaining oral health, the control of biofilms may be inadequate for many people ${ }^{6}$. Notably, although tooth brushing is considered the first-line oral hygiene care method, its biofilm-removal effect may be limited in certain patients or specific areas ${ }^{7}$. Therefore, to achieve optimal oral hygiene status, tooth brushing should be accompanied by the use of chemotherapeutic agents ${ }^{8,9}$.

Among the available antimicrobial agents, chlorhexidine gluconate (CHX) is considered effective for reducing oral biofilms, as well as for preventing and treating gingival inflammation ${ }^{10}$. However, CHX mouth-rinse has many side effects, including staining of the teeth, tongue, and restorations, as well as increased supragingival calculus formation and altered taste perception ${ }^{8}$. Therefore, researchers have been investigating natural bioactive compounds that may avoid these side effects. In particular, essential oils extracted from cinnamon, sweet basil, peppermint, and spearmint exhibit robust antibacterial activities ${ }^{11}$. Several studies have shown that cinnamon essential oil (CEO) inhibits the proliferation of Streptococcus mutans and Porphyromonas gingivalis, pathogenic bacteria that cause oral diseases, and the proliferation of Candida albicans, a pathogenic fungus implicated in the occurrence of denture-induced stomatitis ${ }^{12,13}$. Another study showed that CEO interfered with the formation of single-species biofilms formed using specific oral strains ${ }^{11}$. Although CEO reportedly exhibits antibacterial effects against a wide array of pathogenic oral bacteria, more information is needed regarding whether it can sufficiently suppress the formation of multi-species biofilms, which is essential for the prevention of oral diseases. Notably, oral diseases are caused by systematic and complex interactions among biofilms of more than 700 species of

${ }^{1}$ Department of Health Science, Graduate School of Gachon University, Incheon, Republic of Korea. ${ }^{2}$ Department of Dental Hygiene, College of Health Science, Gachon University, 191 Hambakmoero Yeonsu-gu, Incheon 21936, Republic of Korea. ${ }^{\boxplus}$ email: junseon@gachon.ac.kr 


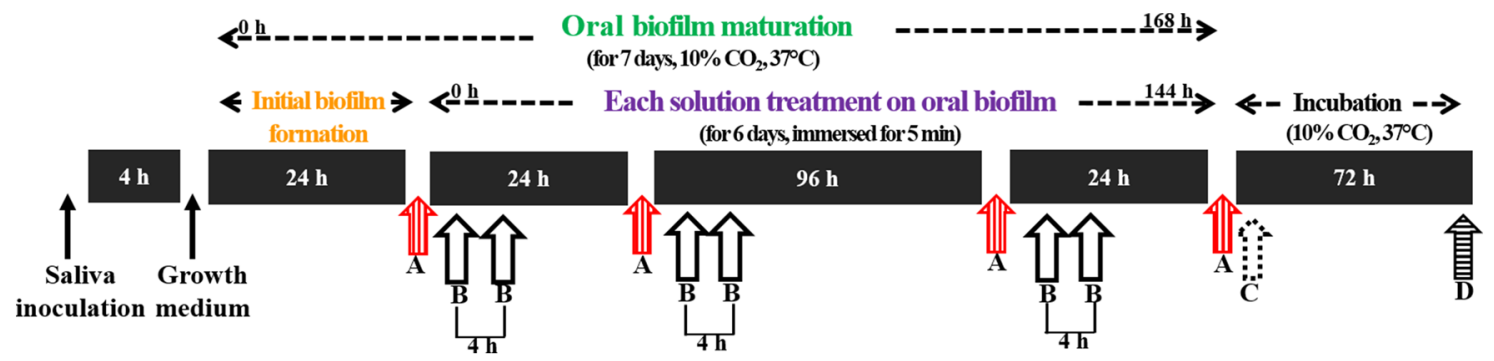

Figure 1. Flow chart of the experimental procedures. QLF-D quantitative light-induced fluorescence-digita, CEON cinnamon essential oil nanoemulsion, $C H X$ chlorhexidine gluconate, $C B$ cocamidopropyl betaine, $C F U s$ colony-forming units. A: QLF-D analysis. B: Treatment of oral biofilms with $5 \%$ CEON, $0.12 \%$ CHX, or $0.5 \%$ CB. C: Harvest and absorbance measurement of oral biofilms. D: Assessment of aciduric bacteria CFUs.

oral microorganisms, rather than by single species of bacteria in isolation ${ }^{14,15}$. More importantly, $80-90 \%$ of the matrixes in oral biofilms are composed of water ${ }^{9}$. Thus, to allow lipophilic CEO to penetrate into deep layers of oral biofilms, the oil must be emulsified with appropriate technology. However, there has been minimal research regarding the ability of CEO to inhibit multi-species biofilms present in the oral cavity.

Therefore, this study was performed to investigate whether cinnamon essential oil nanoemulsion (CEON) could inhibit the maturation of microcosm biofilms derived from saliva, by using quantitative light-induced fluorescence-digital (QLF-D), an optical device that visualizes pathogenic oral biofilms via red fluorescence. Furthermore, this study investigated the antibacterial effect of CEON against caries-causing aciduric bacteria in biofilms, as well as the growth-inhibiting effect of CEON against oral microorganisms in biofilms.

\section{Materials and methods}

Experimental design. This experimental in vitro study using bovine incisors was conducted from April 1, 2019 to December 30,2019. Its protocol was approved by the Institutional Review Board of Gachon University, South Korea (approval no. 1044396-201904-HR-057-01). All experimental procedures were performed in full accordance with the Board's relevant guidelines and regulations. In addition, saliva was collected from an adult volunteer following the acquisition of written informed consent, in accordance with the World Medical Association Declaration of Helsinki.

An oral microcosm biofilm model using human saliva as an inoculum was employed, which allowed the maturation of biofilms on bovine incisors for 7 days. On the maturing biofilms, one of three solutions, $5 \%$ CEON, $0.12 \% \mathrm{CHX}$ (positive control), or $0.5 \%$ cocamidopropyl betaine ( $\mathrm{CB}$, negative control), was applied twice per day for 6 days. To quantitatively analyze the inhibitory effects of the solutions on the formation of biofilms, specimens with biofilms were photographed using the QLF-D Biluminator (Inspektor Research Systems BV, Netherlands) once per day. QLF-D is a device that visualizes pathogenic oral biofilms via red fluorescence of porphyrin compounds, which are metabolites produced by oral bacteria species, using $405 \mathrm{~nm}$ visible blue light ${ }^{16}$. QLF-D has been recognized as a valuable tool for objectively and quantitatively evaluating the maturation of biofilms ${ }^{16,17}$. In addition, to evaluate growth inhibition of oral microorganisms in biofilms, absorbance was measured using the Multiskan FC Microplate Photometer (Thermo Fisher Scientific Inc., USA). Finally, to evaluate antibacterial effects against aciduric bacteria in biofilms, colony-forming units (CFUs) were counted. All analyses were performed by a single trained examiner. A brief summary of the experimental procedures is provided in Fig. 1.

Preparation of enamel specimens. Enamel specimens were made using bovine incisors to generate oral biofilms. The 105 intact bovine incisors used in this study were collected from one slaughterhouse (Incheon, South Korea) following official approval by Incheon City. The mean age of the slaughtered animals was 3 years. Using the method described by Kim et al. ${ }^{16}$, the dental crowns of bovine incisors without cracks and white spots were separated from the corresponding roots, and their labial surfaces were sectioned with a low-speed saw using a diamond-coated disc $(6 \mathrm{~mm} \times 5 \mathrm{~mm})$. The specimens were then embedded in a circular acrylic mold using a dental impression material. The exposed enamel surfaces were ground flat with a water-cooled polishing unit (M-Prep 5; Allied High Tech Products Inc., USA) using 360-grit abrasive sandpaper for $20 \mathrm{s,} 600$-grit paper for $20 \mathrm{~s}$, and 1200-grit paper for $10 \mathrm{~s}$ (SiC Sand Paper; R\&B Inc., South Korea) operating at $100 \mathrm{rpm}$. Finally, to secure space for the accumulation of oral biofilms, the specimen was re-embedded $1 \mathrm{~mm}$ below the peak of the acrylic mold. The minimum number of specimens required for one-way analysis of variance was determined to be 102, based on a power calculation done using $\mathrm{G}^{*}$ Power 3.1 (Franz Faul, Germany) with the following parameters: $95 \%$ power, $5 \%$ significance level, and 0.4 effect size $^{18}$. The specimens were randomly assigned to one of the following three groups: $5 \%$ CEON $(n=35), 0.12$ CHX $(n=35)$, or 0.5\% CB $(n=35)$.

Preparation of CEON. An essential oil extracted from cinnamon (Cinnamomum verum) bark by steam distillation was purchased from dōTERRA International, LLC (USA). Steam distillation is a technique that can extract many components inhibiting the growth of microorganisms, and has been widely used in various studies ${ }^{19,20}$. The chemical constituents of this CEO were analyzed using gas chromatography-mass spectrometry (7890A/5975C; Agilent Technologies, USA). An HP-5MS fused-silica capillary column (30 $\mathrm{m} \times 0.25 \mathrm{~mm} \times 0.25 \mu \mathrm{m})$ was used. The operating conditions were as follows: initial oven temperature, $40^{\circ} \mathrm{C}$ for $5 \mathrm{~min}, 10^{\circ} \mathrm{C}$ for $5 \mathrm{~min}$, and $280^{\circ} \mathrm{C}$ 
for $5 \mathrm{~min}$; inlet temperature, $250{ }^{\circ} \mathrm{C}$; carrier gas, $1.0 \mathrm{~mL} / \mathrm{min}$ helium; injection volume, $1 \mu \mathrm{L}$; split ratio, 10:1; electron ionization voltage, $70 \mathrm{eV}$; mass spectrometer ion source temperature, $230{ }^{\circ} \mathrm{C}$; and mass spectrometer scan range, $30-500 \mathrm{~m} / \mathrm{z}$. All components of the CEO were identified by comparing their mass spectra with the standard mass spectra provided by the NIST 11 library. The results showed that cinnamaldehyde constituted $>50 \%$ of the total peak area $(61.80 \%)$. Fourteen other compounds were identified, including acetic acid cinnamyl ester (7.81\%), caryophyllene (6.89\%), $\beta$-thujene (5.70\%), 3-allyl-6-methoxyphenol (4.35\%), o-cymene $(2.77 \%)$, and $\alpha$-phellandrene $(2.06 \%)$ (seven compounds of less than $2 \%$ are not shown). To determine the concentration of CEO used for treatment of biofilms, a disc diffusion assay was performed to measure its antibacterial activity against oral microorganisms present in saliva, because saliva contains most of the bacteria in oral biofilms ${ }^{21}$. Furthermore, several preliminary studies were performed, including minimal biofilm inhibitory concentration analysis, using the Multiskan FC Microplate Photometer (Thermo Fisher Scientific Inc.). Based on the analysis results, the concentration of CEO used in this study was set at $5 \%$. In addition, to improve delivery of the CEO active ingredients, the oil was formulated in an oil-in-water type emulsion with nano-sized oil droplets, on the basis of several previous studies ${ }^{22,23}$. CB (Combi-Blocks Inc., USA), a biosurfactant, and an ultrasonicator (VCX 750; Sonics \& Materials Inc., USA) were used for emulsification. Initially, stock CEO (5 mL) was dissolved in $0.5 \% \mathrm{CB}(0.5 \mathrm{~mL})$. It was then diluted in sterile distilled water $(94.5 \mathrm{~mL})$ to prepare a $5 \% \mathrm{CEO}$ emulsion. To minimize the size of the oil droplets, the emulsion was subjected to high-intensity ultrasonication for 5 min using an ultrasonicator (VCX 750; Sonics \& Materials Inc.), as follows: pulse, start for $2 \mathrm{~s}$ and stop for $3 \mathrm{~s}$; frequency, $20 \mathrm{kHz}$; amplitude, 20\%. Finally, a vortex mixer (VM-96A; Lab Companion, South Korea) was operated at $3000 \mathrm{rpm}$ for $5 \mathrm{~min}$ to remix the CEON immediately before addition to biofilms.

The mean size of the oil droplets in the formulated emulsion was analyzed using a zeta potential and particle size analyzer (ELSZ-2000ZS; Otsuka Electronics, Japan). The size was measured three times in succession at $25^{\circ} \mathrm{C}$ by means of dynamic light scattering, which is the most commonly used technique for nanoparticle sizing. The oil droplet size was $206.2 \mathrm{~nm}$ in the first round, $208.2 \mathrm{~nm}$ in the second round, and $207.1 \mathrm{~nm}$ in the third round. The mean droplet size was $207.2 \mathrm{~nm}$ (data not shown).

Formation of microcosm oral biofilms and treatment with three solutions. To induce the growth of multi-species pathogenic biofilms, the biofilms were formed on enamel specimens for 7 days under a basal medium mucin with $0.5 \%$ sucrose, based on an established oral microcosm biofilm model ${ }^{16,24-26}$. The basal medium of synthetic saliva contained $2.5 \mathrm{~g} / \mathrm{L}$ porcine mucin (Type III; Sigma-Aldrich, USA), $10.0 \mathrm{~g} / \mathrm{L}$ proteose peptone (KisanBio, South Korea), 5.0 g/L trypticase peptone (KisanBio), $5.0 \mathrm{~g} / \mathrm{L}$ yeast extract (KisanBio), $1 \mathrm{mmol} / \mathrm{L}$ urea (GeorgiaChem, USA), $1 \mathrm{mmol} / \mathrm{L}$ arginine (GeorgiaChem), $2.5 \mathrm{~g} / \mathrm{L}$ potassium chloride (OCI Co., South Korea), $5 \mathrm{mg} / \mathrm{L}$ hemin (Sigma-Aldrich, USA), and $1 \mathrm{mg} / \mathrm{L}$ menadione (Sigma-Aldrich). This medium was adjusted to $\mathrm{pH} 7.0$ using a 50\% sodium hydroxide solution (Daejung Chemicals \& Metals Co., South Korea). On the maturing biofilms, one of the three treatment solutions, i.e., 5\% CEON, 0.12\% CHX (Unimed Pharmaceuticals Inc., South Korea) or 0.5\% CB (Combi-Blocks Inc.), was applied twice per day at 4-h intervals for 6 days. First, whole stimulated saliva to be used as the inoculum was collected from a healthy woman who did not have any active dental caries or periodontal diseases, and had not taken antibiotics in the preceding 3 months. The donor was instructed not to perform any oral hygiene practices for $24 \mathrm{~h}$ prior to saliva collection. The stimulated saliva was collected using paraffin wax (Ivoclar Vivadent, Germany) and then filtered through sterilized glass wool (Duksan Pure Chemical, South Korea). The prepared saliva $(1.5 \mathrm{~mL})$ was immediately used to inoculate enamel specimens in a 24 -well cell culture plate, and the plate was incubated anaerobically at $37^{\circ} \mathrm{C}$ for $4 \mathrm{~h}$. Next, the saliva was aspirated from the well, and $1.5 \mathrm{~mL}$ growth medium was added (mixture of $0.1 \mathrm{~mL}$ of $0.5 \%$ sucrose and $1.4 \mathrm{~mL}$ of basal medium mucin). The plate was again incubated at $37^{\circ} \mathrm{C}$ with $10 \% \mathrm{CO}_{2}$ for $24 \mathrm{~h}$. After $24 \mathrm{~h}$, the specimens on which biofilms had initially formed were immersed in $1.5 \mathrm{~mL}$ of one of the three treatment solutions in each well of a 24 -well plate for $5 \mathrm{~min}$. Next, the specimens treated with biofilms were gently washed with $1.5 \mathrm{~mL}$ sterile distilled water in a new well for $5 \mathrm{~s}$, and then carefully placed into a new well in a 24-well plate containing new basal medium mucin $(1.5 \mathrm{~mL})$. The plate was incubated again under the same culture conditions. After $4 \mathrm{~h}$, a second treatment was performed on each specimen with biofilms in the manner described above. All treatment procedures were repeated for 6 days.

Analysis of antibacterial and antibiofilm activities of the three treatment solutions. Inhibitory effect against formation of oral biofilms. To evaluate the inhibitory effect against formation of oral biofilms, QLF-D was used in this study, as in a prior study ${ }^{16,17,24}$. Biofilms were photographed once per day, immediately prior to treatment with the designated solution. QLF-D images were taken under the following conditions, while maintaining a consistent distance between the camera lens and each specimen of biofilm: shutter speed, 1/60 s; aperture value, 5.0; and ISO speed, $1600^{27}$. For fluorescence images, red and green values in the same area on each biofilm specimen were analyzed. The mean red/green ratio (R/G values) was then calculated using the ImageJ image analysis program (version 1.46; NIH, USA). Higher R/G values were presumed to indicate advanced maturity and greater pathogenicity ${ }^{16,27}$.

Antimicrobial effect against aciduric bacteria in biofilms. Colony-forming units (CFUs/mL) were counted to evaluate the antibacterial effect against aciduric bacteria in biofilms ${ }^{28}$. Briefly, $24 \mathrm{~h}$ after biofilms had received the final treatment with the designated solution, the specimens with biofilms were rinsed with sterile distilled water $(1.5 \mathrm{~mL})$ to remove the remaining growth medium. Then, specimens were transferred into conical tubes containing $2 \mathrm{~mL}$ of distilled water, and the attached biofilms were dispersed using a sonicator (SHB-1025; Saehan Sonic, South Korea) and a vortex mixer (VM-96A; Jeio Tech, South Korea) (1 min each). The prepared bacterial suspensions were serially diluted $\left(10^{-1}-10^{-6}\right)$ and spread on brain heart infusion agar plates adjusted to $\mathrm{pH} 4.8$. 


\begin{tabular}{|c|c|c|c|c|c|c|}
\hline \multirow[b]{2}{*}{ Groups } & \multirow[b]{2}{*}{ Treatment solutions } & \multirow[b]{2}{*}{$\mathbf{N}$} & \multicolumn{4}{|l|}{$\mathrm{R} / \mathrm{G}$ values } \\
\hline & & & Baseline & $F(p)$ & 7-day-old mature biofilms & $F(p)$ \\
\hline Experimental & $5 \% \mathrm{CEON}$ & 35 & $0.77 \pm 0.05$ & \multirow{3}{*}{$1.951(0.147)$} & $0.91 \pm 0.10^{\mathrm{a}}$ & \multirow{3}{*}{$111.281(<0.001)$} \\
\hline Positive control & $0.12 \% \mathrm{CHX}$ & 35 & $0.79 \pm 0.05$ & & $0.87 \pm 0.09^{\mathrm{a}}$ & \\
\hline Negative control & $0.5 \% \mathrm{CB}$ & 35 & $0.79 \pm 0.06$ & & $1.18 \pm 0.07^{\mathrm{b}}$ & \\
\hline
\end{tabular}

Table 1. R/G values of 7-day-old mature biofilms according to treatment solution. CEON cinnamon essential oil nanoemulsion, $C H X$ chlorhexidine gluconate, $C B$ cocamidopropyl betaine. $p$ values obtained from oneway analysis of variance. All values are expressed as means \pm standard deviations. ${ }^{\mathrm{a} b}$ Different letters indicate significance by Bonferroni multiple comparison test at $\alpha=0.05$.

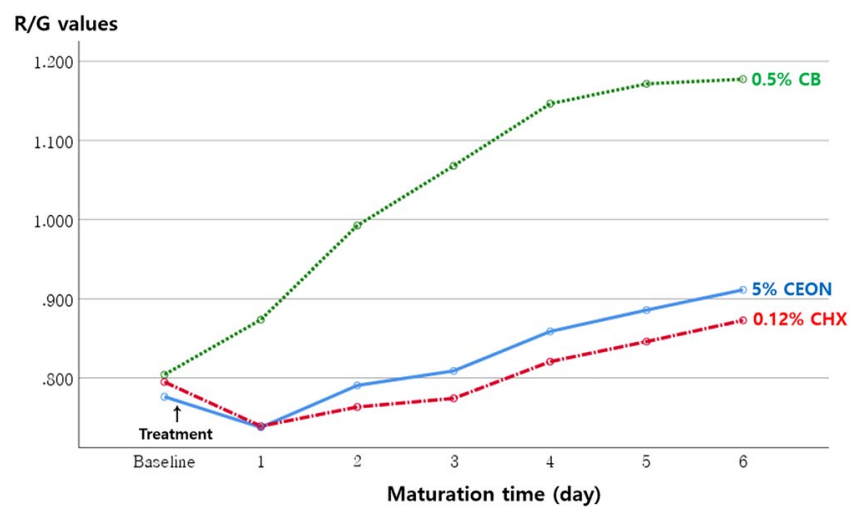

Figure 2. Changes in $\mathrm{R} / \mathrm{G}$ values of oral biofilms formed in the presence of three treatment solutions according to maturation time. $C E O N$ cinnamon essential oil nanoemulsion, $C H X$ chlorhexidine gluconate, $C B$ cocamidopropyl betaine.

The plates were incubated anaerobically at $37^{\circ} \mathrm{C}$ with $10 \% \mathrm{CO}_{2}$ for $72 \mathrm{~h}$, and the number of aciduric bacterial CFUs was counted by a single examiner. A higher number of CFUs was presumed to indicate that aciduric bacteria were more prevalent in biofilms ${ }^{16}$.

Inhibitory effect against oral microorganism growth in biofilms. Absorbance was measured using the Multiskan FC Microplate Photometer (Thermo Fisher Scientific Inc.), to quantify the inhibitory effect against oral microorganism growth in biofilms. Each diluted bacterial suspension $(100 \mu \mathrm{L})$, identical to the suspension used for analyzing the antimicrobial effect against aciduric bacteria, was transferred into a new 96-well plate and its absorbance was then measured at a wavelength of $595 \mathrm{~nm}$ using the method described by Jeong et al. ${ }^{29}$. A lower absorbance was presumed to indicate greater inhibition of oral microorganism growth.

Statistical analysis. For statistical analysis, IBM SPSS Statistics (ver. 23.0; IBM Corp., USA) was used, and $p<0.05$ was considered to indicate statistical significance. Regarding the R/G values of biofilms, two-way repeated-measures analysis of variance, followed by the Bonferroni post hoc test, was performed to verify the interaction effects between time and each treatment group. To compare the number of aciduric bacterial CFUs in biofilms and the absorbance of bacterial suspensions among the three treatment solutions, one-way analysis of variance and Scheffe's post hoc test were performed.

\section{Results}

R/G values of 7-day-old mature biofilms according to treatment solution. The R/G values of 7-day-old mature biofilms exposed to each of the treatment solutions are shown in Table 1. The R/G values of initial biofilms before applying the treatment solutions to the specimens did not differ significantly among the three groups $(p>0.05)$. After applying the treatment solutions, the $\mathrm{R} / \mathrm{G}$ values of biofilms differed significantly between the $5 \% \mathrm{CEON}$ and $0.5 \% \mathrm{CB}$ groups at all maturation time points, but not between the $5 \% \mathrm{CEON}$ and $0.12 \%$ CHX groups $(p>0.05$, Fig. 2$)$. The R/G values of 7 -day-old mature biofilms were lowest in the $0.12 \%$ CHX group $(0.87 \pm 0.09)$, followed by the $5 \%$ CEON group $(0.91 \pm 0.10)$ and the $0.5 \%$ CB group $(1.18 \pm 0.07)$ $(p<0.001)$. There was no significant difference in $\mathrm{R} / \mathrm{G}$ values between the $5 \% \mathrm{CEON}$ and $0.12 \%$ CHX groups $(p>0.05)$. Representative QLF-D red fluorescence images of 7-day-old mature biofilms for each treatment solution are shown in Fig. 3.

Aciduric bacterial CFUs within biofilms according to treatment solution. The aciduric bacterial CFUs within biofilms exposed to each treatment solution are shown in Table 2 . The number of aciduric bacterial CFUs was lowest in the $5 \%$ CEON group $(4.81 \pm 2.03)$, but this did not significantly differ from the number in 

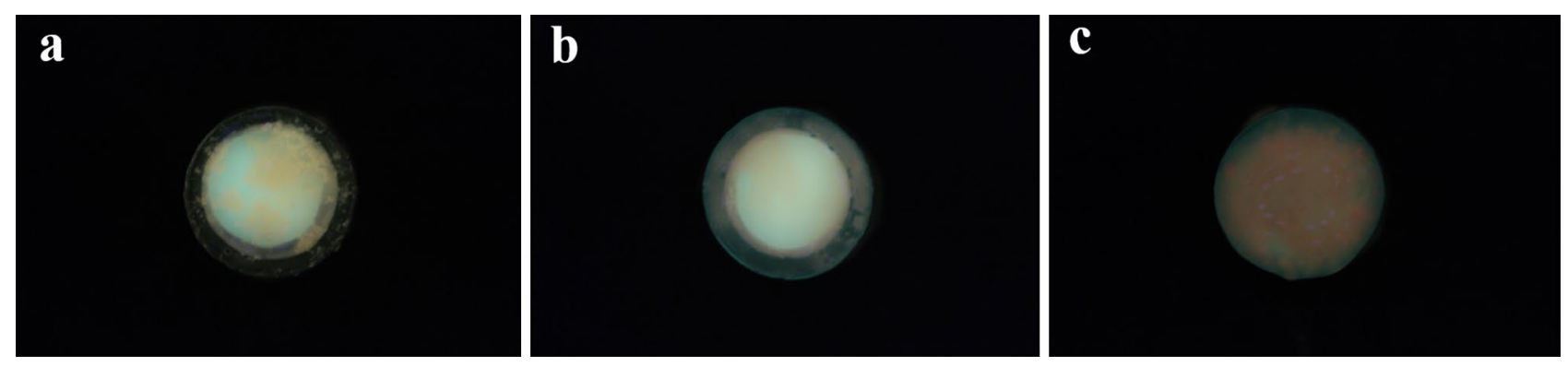

Figure 3. QLF-D red fluorescence images of 7-day-old mature oral biofilms after treatment with 5\% CEON (a), $0.12 \% \mathrm{CHX}(\mathbf{b})$, and $0.5 \% \mathrm{CB}(\mathbf{c})$. CEON cinnamon essential oil nanoemulsion, $C H X$ chlorhexidine gluconate, $C B$ cocamidopropyl betaine.

\begin{tabular}{|c|c|c|c|c|c|}
\hline Groups & Treatment solutions & $\mathbf{N}$ & $\log _{10}$ CFUs/mL & $\mathbf{F}$ & $p$ \\
\hline Experimental & $5 \% \mathrm{CEON}$ & 35 & $4.81 \pm 2.03^{\mathrm{a}}$ & \multirow{3}{*}{19.823} & \multirow{3}{*}{$<0.001$} \\
\hline Positive control & $0.12 \% \mathrm{CHX}$ & 35 & $5.11 \pm 1.65^{\mathrm{a}}$ & & \\
\hline Negative control & $0.5 \% \mathrm{CB}$ & 35 & $6.93 \pm 0.31^{b}$ & & \\
\hline
\end{tabular}

Table 2. Numbers of aciduric bacterial CFUs within biofilms according to treatment solution. CFUs colony-forming units, $C E O N$ cinnamon essential oil nanoemulsion, $C H X$ chlorhexidine gluconate, $C B$ cocamidopropyl betaine. $p$ value obtained from one-way analysis of variance. All values are presented as means \pm standard deviations. ${ }^{\mathrm{a}, \mathrm{b}}$ Different letters indicate significance by Scheffe's multiple comparison test at $\alpha=0.05$.

\begin{tabular}{|c|c|c|c|c|c|}
\hline Groups & Treatment solutions & $\mathbf{N}$ & Absorbance & $\mathbf{F}$ & $p$ \\
\hline Experimental & $5 \% \mathrm{CEON}$ & 35 & $0.29 \pm 0.16^{\mathrm{a}}$ & \multirow{3}{*}{346.725} & \multirow{3}{*}{$<0.001$} \\
\hline Positive control & $0.12 \%$ CHX & 35 & $0.36 \pm 0.10^{\mathrm{a}}$ & & \\
\hline Negative control & $0.5 \% \mathrm{CB}$ & 35 & $1.14 \pm 0.17^{\mathrm{b}}$ & & \\
\hline
\end{tabular}

Table 3. Absorbance of oral bacterial suspensions according to treatment solution. CEON cinnamon essential oil nanoemulsion, $C H X$ chlorhexidine gluconate, $C B$ cocamidopropyl betaine. $p$ value obtained from oneway analysis of variance. All values are expressed as means \pm standard deviations. ${ }^{\mathrm{a}, \mathrm{b}}$ Different letters indicate significance by Scheffe's multiple comparison test at $\alpha=0.05$.

the $0.12 \%$ CHX group $(5.11 \pm 1.65, p>0.05)$. The number of CFUs was highest in the $0.5 \%$ CB group $(6.93 \pm 0.31$, $p<0.001)$.

Absorbances of bacterial suspensions according to treatment solution. The absorbances of bacterial suspensions exposed to each of the treatment solutions are shown in Table 3 . The absorbance was lowest in the $5 \%$ CEON group $(0.29 \pm 0.16)$ and highest in the $0.5 \% \mathrm{CB}$ group $(1.14 \pm 0.17, p<0.001)$. The absorbance of the $5 \%$ CEON group was not significantly different from that of the $0.12 \% \mathrm{CHX}$ group $(0.36 \pm 0.10, p>0.05)$.

\section{Discussion}

This study evaluated the antibacterial and antibiofilm activities of 5\% CEON against multi-species biofilms, which are the root cause of oral disease. In general, to achieve a robust antibacterial effect from CEO, the oil must be pre-treated prior to application, considering the nature of the target, due to the lipophilic characteristics of the $\mathrm{CEO}^{30}$. The oral biofilms were mostly composed of water ${ }^{9}$, and the oral microorganisms present in the biofilms were embedded within a self-produced matrix of extracellular polymeric compounds ${ }^{3,9,31}$. Although cinnamaldehyde (a major constituent of CEO that substantially contributes to its antibacterial properties) is biocompatible and low in toxicity ${ }^{32,33}$, oral adverse reactions have been reported sporadically, such as intraoral allergic reactions and contact stomatitis when used at high concentrations ${ }^{34,35}$. Accordingly, the concentration of $\mathrm{CEO}$ in a treatment solution should be as low as possible to minimize possible side effects from the components of cinnamon. Therefore, considering these characteristics of oral biofilms and CEO, we used CB, an organic surfactant with low toxicity ${ }^{36}$, distilled water, and high-intensity ultrasonic waves to produce an oil-in-water type of CEON. Ultrasonication is a technique that contributes to the conversion from a coarse emulsion to a nano-sized emulsion by reducing the oil droplet size ${ }^{37}$. We applied this $5 \% \mathrm{CEON}$, containing oil droplets with a mean size of approximately $200 \mathrm{~nm}$, onto maturing biofilms twice per day for 6 days, and then compared the effects of 5\% CEON with those of two other treatment solutions. The results showed that the red fluorescence intensity of 7 -day-old mature biofilms was lowest in the $0.12 \%$ CHX group, which was not significantly different from the intensity in the $5 \% \mathrm{CEON}$ group. In addition, the $\mathrm{R} / \mathrm{G}$ values of biofilms did not significantly differ between the 
$5 \% \mathrm{CEON}$ and $0.12 \% \mathrm{CHX}$ groups at all maturation time points, whereas significant differences were observed between the $5 \% \mathrm{CEON}$ and $0.5 \% \mathrm{CB}$ groups (Fig. 2). Thus, $5 \% \mathrm{CEON}$ was similar to $0.12 \% \mathrm{CHX}$ in terms of its ability to significantly inhibit the maturation of both early biofilms and mature biofilms, even when the biofilms were incubated in an optimal environment for enhancement of pathogenicity. Furthermore, in the 5\% CEON group, the growth of oral microorganisms, including caries-causing aciduric bacteria, was suppressed the most. We confirmed that this effect was not significantly different from that of the CHX solution, the current goldstandard antimicrobial agent.

We could not directly compare the results of this study with those of previous studies, because we were unable to identify any publications that analyzed the effects of CEO on multi-species oral biofilms. However, our findings are consistent with the results of a study in which a 24-h pre-established Streptococcus mutans biofilm was exposed to $\mathrm{CEO}^{11}$. In that study, the biofilm mass decreased by $>50 \%$, although the oil had been applied to a single-species oral biofilm ${ }^{11}$, in contrast to the present study. We presumed that our nanoemulsion technique (using an ultrasonicator and biosurfactant) contributed to deeper penetration of CEO active ingredients into mature biofilms, thus resulting in significant antibacterial and antibiofilm activities, despite the low CEO concentration. Research on the nanoemulsification of CEO, aiming to enhance its antibacterial activity against dental biofilms, is limited in the dental field. However, compared with conventional emulsions, the smaller droplet diameters of nanoemulsions reportedly facilitate stronger antibacterial properties against gram-positive and gram-negative bacteria ${ }^{38,39}$. In addition, the inhibitory effects of $5 \% \mathrm{CEON}$ on the growth of oral microorganisms and the formation of pathogenic multi-species oral biofilms, which were demonstrated in the present study, may have been mediated by various active substances within cinnamon (e.g., cinnamaldehyde ${ }^{12,19}$. Although the mechanism underlying the antibacterial effect of CEO has not yet been fully elucidated, these active constituents have been reported to cause cell lysis by cell membrane distortion ${ }^{37}$. In particular, cinnamaldehyde is highly electronegative ${ }^{40}$. Electronegative compounds interfere with biological processes (e.g., electron transfer), react with nitrogen-containing components such as proteins and nucleic acids, and ultimately inhibit microorganism growth ${ }^{41}$. In an in vitro study of cariogenic bacteria, aqueous cinnamon extract effectively suppressed acid production by Streptococcus mutans, as well as its bacterial adhesion ${ }^{42}$. In a study by Zainal-Abidin et al. ${ }^{12}$, CEO inhibited the proliferation of Porphyromonas gingivalis and Fusobacterium nucleatum, two periodontopathic bacteria, by inducing changes in their surface membranes. Wang et al. ${ }^{20}$ observed that higher concentrations of $\mathrm{CEO}$ or cinnamaldehyde led to greater leakage of proteins and nucleic acids. Therefore, on the basis of our findings and the results of previous studies, we recommend consideration of CEO as a potential natural antimicrobial agent that can aid in controlling oral diseases by effectively inhibiting the formation of pathogenic oral biofilms.

To the best of our knowledge, this study is the first to systematically demonstrate that CEON significantly inhibits the maturation of pathogenic multi-species biofilms, which were formed using a microcosm biofilm model. Notably, our study used a QLF-D device that can quantitatively evaluate the maturity of biofilms ${ }^{16}$ and non-destructively monitor the effects of antimicrobial agents against those biofilms ${ }^{27}$.

However, there were some limitations. First, because this was an in vitro study, the antibacterial and antibiofilm activities of 5\% CEON may not reflect those in the actual oral environment, wherein they would interact with saliva. Second, because the treatment period was relatively short, the study only assessed the short-term effect of 5\% CEON. Finally, the properties of biofilms formed on bovine incisors may differ from those of oral biofilms that accumulate on human teeth. Therefore, in future studies, the antibiofilm activity of CEO should be assessed according to both concentration and long-term effectiveness, in a larger number of enamel specimens. Furthermore, understanding the mechanism by which CEON inhibits the maturation of multi-species biofilms could enhance the usefulness of CEO in the prevention and reduction of oral diseases caused by biofilms. Finally, although cinnamon-related contact stomatitis is a relatively uncommon disorder ${ }^{34,43}$, CEON-related hypersensitivity reactions involving the oral mucosa should be evaluated in the future.

Received: 1 December 2020; Accepted: 28 February 2021

Published online: 15 March 2021

\section{References}

1. Fejerskov, O. \& Kidd, E. Dental Caries: The Disease and Its Clinical Management (Blackwell Publishing, 2008).

2. Seneviratne, C. J., Zhang, C. F. \& Samaranayake, L. P. Dental plaque biofilm in oral health and disease. Chin. J. Dent. Res. 14, 87-94 (2011).

3. Yu, O. Y., Zhao, I. S., Mei, M. L., Lo, E. C. M. \& Chu, C. H. Dental biofilm and laboratory microbial culture models for cariology research. Dent. J. (Basel) 5, 21. https://doi.org/10.3390/dj5020021 (2017).

4. Stoodley, P., Sauer, K., Davies, D. G. \& Costerton, J. W. Biofilms as complex differentiated communities. Annu. Rev. Microbiol. 56, 187-209. https://doi.org/10.1146/annurev.micro.56.012302.160705 (2002).

5. Jiang, Q., Stamatova, I., Kainulainen, V., Korpela, R. \& Meurman, J. H. Interactions between Lactobacillus rhamnosus GG and oral micro-organisms in an in vitro biofilm model. BMC. Microbiol. 16, 149. https://doi.org/10.1186/s12866-016-0759-7 (2016).

6. van der Weijden, G. A. \& Hioe, K. P. K. A systematic review of the effectiveness of self-performed mechanical plaque removal in adults with gingivitis using a manual toothbrush. J. Clin. Periodontol. 32, 214-228. https://doi.org/10.1111/j.1600-051X.2005.00795 .x (2005).

7. Arweiler, N. B., Auschill, T. M. \& Sculean, A. Patient self-care of periodontal pocket infections. Periodontol 2000 76, $164-179$. https://doi.org/10.1111/prd.12152 (2018).

8. Wilkins, E. M. Clinical Practice of the Dental hygienists (Lippincott Williams \& Wilkins, 2005).

9. Berger, D., Rakhamimova, A., Pollack, A. \& Loewy, Z. Oral biofilms: Development, control, and analysis. High Throughput 31, 24. https://doi.org/10.3390/ht7030024 (2018).

10. Arweiler, N. B., Boehnke, N., Sculean, A., Hellwig, E. \& Auschill, T. M. Differences in efficacy of two commercial $0.2 \%$ chlorhexidine mouthrinse solutions: A 4-day plaque re-growth study. J. Clin. Periodontol. 33, 334-339. https://doi.org/10.1111/j.1600051X.2006.00917.x (2006).

11. Wiwattanarattanabut, K., Choonharuangdej, S. \& Srithavaj, T. In vitro anti-cariogenic plaque effects of essential oils extracted from culinary herbs. J. Clin. Diagn. Res. 11, 30-35. https://doi.org/10.7860/JCDR/2017/28327.10668 (2017). 
12. Zainal-Abidin, Z. et al. Anti-bacterial activity of cinnamon oil on oral pathogens. Open Conf. Proc. J. 4, 12-16. https://doi. org/10.2174/2210289201304020012 (2013).

13. de Fátima-Dantas-de-Almeid, L. et al. Efficacy of citronella and cinnamon essential oils on Candida albicans biofilms. Acta. Odontol. Scand. 74, 393-398. https://doi.org/10.3109/00016357.2016.1166261 (2016).

14. Hojo, K., Nagaoka, S., Ohshima, T. \& Maeda, N. Bacterial interactions in dental biofilm development. J. Dent. Res. 88, 982-990. https://doi.org/10.1177/0022034509346811 (2009).

15. Dewhirst, F. E. et al. The human oral microbiome. J. Bacteriol. 192, 5002-5017. https://doi.org/10.1128/JB.00542-10 (2010).

16. Kim, Y. S., Lee, E. S., Kwon, H. K. \& Kim, B. I. Monitoring the maturation process of a dental microcosm biofilm using the quantitative light-induced fluorescence-digital (QLF-D). J. Dent. 42, 691-696. https://doi.org/10.1016/j.jdent.2014.03.006 (2014).

17. Han, S. Y., Kim, B. R., Ko, H. Y., Kwon, H. K. \& Kim, B. I. Assessing the use of quantitative light-induced fluorescence-digital as a clinical plaque assessment. Photodiagn. Photodyn. Ther. 13, 34-39. https://doi.org/10.1016/j.pdpdt.2015.12.002 (2016).

18. Faul, F., Erdfelder, E., Buchner, A. \& Lang, G. Statistical power analyses using $\mathrm{G}^{*}$ Power 3.1: Tests for correlation and regression analyses. Behav. Res. Methods 41,1149-1160. https://doi.org/10.3758/BRM.41.4.1149 (2009).

19. Wong, Y. C., Ahmad-Mudzaqqir, M. Y. \& Wan-Nurdiyana, W. A. Extraction of essential oil from cinnamon (Cinnamomum zeylanicum). Orient J. Chem. 30, 37-47. https://doi.org/10.13005/ojc/300105 (2014).

20. Wang, Y. et al. Antibacterial effects of cinnamon (Cinnamomum zeylanicum) bark essential oil on Porphyromonas gingivalis. Microb. Pathog. 116, 26. https://doi.org/10.1016/j.micpath.2018.01.009 (2018).

21. Li, B. et al. Effects of different substrates/growth media on microbial community of saliva-derived biofilm. FEMS. Microbiol. Lett. 364, 123. https://doi.org/10.1093/femsle/fnx123 (2017).

22. Zhang, S., Zhang, M., Fang, Z. \& Liu, Y. Preparation and characterization of blended cloves/cinnamon essential oil nanoemulsions. LWT 75, 316-322. https://doi.org/10.1016/j.lwt.2016.08.046 (2017).

23. Paudel, S. K., Bhargava, K. \& Kotturi, H. Antimicrobial activity of cinnamon oil nanoemulsion against Listeria monocytogenes and Salmonella spp. on melons. LWT 111, 682-687. https://doi.org/10.1016/j.lwt.2019.05.087 (2019).

24. Lee, E. S., Kang, S. M., Ko, H. Y., Kwon, H. K. \& Kim, B. I. Association between the cariogenicity of a dental microcosm biofilm and its red fluorescence detected by quantitative light-induced fluorescence-digital (QLF-D). J. Dent. 41, 1264-1270. https://doi. org/10.1016/j.jdent.2013.08.021 (2013).

25. Wong, L. \& Sissions, C. A comparison of human dental plaque microcosm biofilms grown in an undefined medium and a chemically defined artificial saliva. Arch Ora. Biol. 46, 477-486. https://doi.org/10.1016/s0003-9969(01)00016-4 (2001).

26. Rudney, J. D. et al. A reproducible oral microcosm biofilm model for testing dental materials. J. Appl. Microbiol. 113, 1540-1553. https://doi.org/10.1111/j.1365-2672.2012.05439.x (2013).

27. Lee, E. S., de Josselin de Jong, E., Jung, H. I. \& Kim, B. I. Red fluorescence of dental biofilm as an indicator for assessing the efficacy of antimicrobials. J. Biomed. Opt. 23, 015003. https://doi.org/10.1117/1.JBO.23.1.015003 (2018).

28. Anderson, G. B., Bowden, J., Morrison, E. C. \& Caffesse, R. G. Clinical effects of chlorhexidine mouthwashes on patients undergoing orthodontic treatment. Am. J. Orthod. Dentofacial 111, 606-612. https://doi.org/10.1016/s0889-5406(97)70312-3 (1997).

29. Jeong, D. N., Kim, D. H., Song, K. Y. \& Seo, K. H. Antimicrobial and anti-biofilm activities of Lactobacillus kefiranofaciens DD2 against oral pathogens. J. Oral Microbiol. 10, 1472985. https://doi.org/10.1080/20002297.2018.1472985 (2018).

30. Donsì, F., Annunziata, M., Vincensi, M. \& Ferrari, G. Design of nanoemulsion-based delivery systems of natural antimicrobials: Effect of the emulsifier. J. Biotechnol. 159, 342-350. https://doi.org/10.1016/j.jbiotec.2011.07.001 (2012).

31. Mashima, I. \& Nakazawa, F. The interaction between Streptococcus spp. and Veillonella tobetsuensis in the early stages of oral biofilm formation. J. Bacteriol. 197, 2104-2111. https://doi.org/10.1128/JB.02512-14 (2015).

32. Absalan, A., Mesbah-Namin, S. A., Tiraihi, T. \& Taheri, T. The effects of cinnamaldehyde and eugenol on human adipose-derived mesenchymal stem cells viability, growth and differentiation: A cheminformatics and in vitro study. Avicenna J. Phytomed. 6, 643-657 (2016).

33. Shreaz, S. et al. Cinnamaldehyde and its derivatives, a novel class of antifungal agents. Fitoterapia 112, 116-131. https://doi. org/10.1016/j.fitote.2016.05.016 (2016).

34. Calapai, G., Miroddi, M., Mannucci, C., Minciullo, P. L. \& Gangemi, S. Oral adverse reactions due to cinnamon-flavoured chewing gums consumption. Oral Dis. 20, 637-643. https://doi.org/10.1111/odi.12170 (2014).

35. Isaac-Renton, M., Li, M. K. \& Parsons, L. M. Cinnamon spice and everything not nice: Many features of intraoral allergy to cinnamic aldehyde. Dermatitis 26, 116-121. https://doi.org/10.1097/DER.0000000000000112 (2015).

36. Burnett, C. L. et al. Final report of the cosmetic ingredient review expert panel on the safety assessment of cocamidopropyl betaine (CAPB). Int. J. Toxicol. 31, 77S-111S. https://doi.org/10.1177/1091581812447202 (2012).

37. Ghosh, V., Saranya, S., Mukherjee, A. \& Chandrasekaran, N. Cinnamon oil nanoemulsion formulation by ultrasonic emulsification: Investigation of its bactericidal activity. J. Nanosci. Nanotechnol. 13, 114-122. https://doi.org/10.1166/jnn.2013.6701 (2013).

38. Pongsumpun, P., Iwamoto, S. \& Siripatrawan, U. Response surface methodology for optimization of cinnamon essential oil nanoemulsion with improved stability and antifungal activity. Ultrason. Sonochem. 60, 104604. https://doi.org/10.1016/j.ultso nch.2019.05.021 (2020).

39. Salvia-Trujillo, L., Rojas-Graü, M. A., Soliva-Fortuny, R. \& Martín-Belloso, O. Use of antimicrobial nanoemulsions as edible coatings: Impact on safety and quality attributes of fresh-cut Fuji apples. Postharvest. Biol. Technol. 105, 8-16. https://doi.org/10.1016/j. postharvbio.2015.03.009 (2015).

40. Gupta, C., Garg, A. P., Uniyal, R. C. \& Kumari, A. Comparative analysis of the antimicrobial activity of cinnamon oil and cinnamon extract on some food-borne microbes. Afr. J. Microbiol. Res. 2, 247-251. https://doi.org/10.5897/AJMR.9000180 (2008).

41. Dorman, H. J. \& Deans, S. G. Antimicrobial agents from plants: Antibacterial activity of plant volatile oils. J. Appl. Microbiol. 88, 308-316. https://doi.org/10.1046/j.1365-2672.2000.00969.x (2000).

42. Kim, H. Y. \& Park, J. B. In vitro evaluation of anti-caries effect of cinnamon extracts on oral pathogens. Biomed. Res. 28, 2848-2853 (2017).

43. Vivas, A. P. M. \& Migliari, D. A. Cinnamon-induced oral mucosal contact reaction. Open Dent. J. 31, 257-259. https://doi. org/10.2174/1874210601509010257 (2015).

\section{Acknowledgements}

We thank all of the participants in this study. This study did not receive any financial support.

\section{Author contributions}

All authors contributed to the writing of the manuscript. Y.J. and J.S. designed the study; Y.J. prepared the tests for the study; Y.J. and J.S. generated the data; Y.J. and J.S. analyzed the data; Y.J., H.E., S.J. and J.S. interpreted the data; H.E. and S.J. supervised the study; Y.J. and J.S. wrote the main manuscript.

\section{Competing interests}

The authors declare no competing interests. 


\section{Additional information}

Correspondence and requests for materials should be addressed to J.-S.C.

Reprints and permissions information is available at www.nature.com/reprints.

Publisher's note Springer Nature remains neutral with regard to jurisdictional claims in published maps and institutional affiliations.

(c) (1) Open Access This article is licensed under a Creative Commons Attribution 4.0 International License, which permits use, sharing, adaptation, distribution and reproduction in any medium or format, as long as you give appropriate credit to the original author(s) and the source, provide a link to the Creative Commons licence, and indicate if changes were made. The images or other third party material in this article are included in the article's Creative Commons licence, unless indicated otherwise in a credit line to the material. If material is not included in the article's Creative Commons licence and your intended use is not permitted by statutory regulation or exceeds the permitted use, you will need to obtain permission directly from the copyright holder. To view a copy of this licence, visit http://creativecommons.org/licenses/by/4.0/.

(C) The Author(s) 2021 